\title{
Association between objective and subjective measurements of comfort and discomfort in hand tools
}

Kuijt-Evers, L.F.M., Bosch, T., Huysmans, M.A., Looze, M.P. de, Vink, P., 2007. Association between objective and subjective measures of comfort and discomfort in hand tools. Applied Ergonomics. 38: 643654.

\begin{abstract}
In the current study the relationship between objective measurements and subjective experienced comfort and discomfort in using hand saws was examined. 12 carpenters evaluated five different hand saws. Objective measures of contact pressure (average pressure, pressure area and P-t integral) in static and dynamic conditions, muscle activity (EMG) of five muscles of the upper extremity, and productivity were obtained during a sawing task. Subjective comfort and discomfort were assessed using the Comfort Questionnaire for Hand tools and a scale for Local Perceived Discomfort (LPD). We did not find any relationship between muscle activity and comfort or discomfort. The P-t integral during the static measurement (beta $=-0.24, \mathrm{p}<.01$ ) was the best predictor of comfort and the pressure area during static measurement was the best predictor of local perceived discomfort (beta $=0.45, \mathrm{p}<.01$ ). Additionally, productivity was highly correlated to comfort (beta $=0.31, \mathrm{p}<.01$ ) and discomfort (beta $=-0.49, \mathrm{p}<.01$ ).
\end{abstract}

keywords: comfort/discomfort, hand tools, objective measurements

\subsection{Introduction}

Tool design may play an important role in the development of work-related problems in the hand and forearm. By improving the ergonomic properties of hand tools the health of users and their job satisfaction might be positively affected (Kadefors et al., 1993). In order to recognize ergonomically well-designed and comfortable hand tools, many hand tool evaluation studies have been conducted. Most studies combined objective measurements (to measure physical load) with subjective experiences of the subjects (to measure comfort or discomfort; e.g., Kluth et al., 2004; Strasser et al., 1996; Groenesteijn et al., 2004; Chang et al., 1999; Li, 2003; Kong and Freivalds, 2003, Freund et al., 2000).

Subjective measurements are most common when hand tools are evaluated with respect to comfort and discomfort. Most of them are focussed on discomfort experience. Methods to assess discomfort are 1) assessing the intensity of discomfort using a map of the palmar side of 
the hand (Groenesteijn et al., 2004; Kilbom et al., 1993; Kuijt-Evers et al., 2005), 2) rating handle discomfort (Kong and Freivalds, 2003; Chang et al., 1999) and 3) rating discomfort of whole body and hand (Kilbom et al., 1993). In other studies, properties of hand tools are evaluated like general handiness, and suitability for longer work (Kluth et al., 2004; Freund et al., 2000; Strasser, 1996; Chang et al., 1999; Groenesteijn et al., 2004). Comfort experience is considered in only a few hand tool evaluation studies (Kuijt-Evers et al., 2005; Freund et al., 2000).

Subjective evaluations have some clear disadvantages: they require a large number of subjects and are therefore time-consuming (Lee et al., 1993), and they are influenced by personal preferences (Chen et al., 1994) (e.g., using always the same brand). Moreover, there are some common known sources of unreliability of using subjective measures, like time error and context effects (Annet, 2002). In some cases, factors which have nothing to do with comfort or discomfort may influence the results. Therefore, objective measurements are used in addition to subjective measurements (e.g., electromyography (EMG) (e.g., Strasser et al., 1996; Fellows and Freivalds, 1991; Freund et al., 2000; Habes and Grant, 1997; Niemelä et al., 2000; Chang et al., 1999; Kadefors et al., 1993), hand-wrist postures (Eikhout et al., 2001; Kadefors et al., 1993), and grip force distribution and grip force (Fellows and Freivalds, 1991; Chang et al., 1999; McGorry, 2003). All the above mentioned objective measures have proven to discriminate between hand tools. For example, differences in EMG were found between different types of masons' trowels, file handles, shovel handles and plate shears (Strasser et al., 1996; Kluth et al., 2004; Chang et al., 1999; Kilbom et al., 1993). A new designed scraper influenced hand-wrist postures (Eikhout et al., 2001) and grip force was found to discriminate between different types of plate-shears, meat cutting knives and shovel handles (Kilbom et al.,1993; McGorry et al., 2003; Chang et al., 1999).

In the previous paragraphs, we argued that subjective measurements are preferred when evaluating hand tools on comfort and discomfort, as comfort and discomfort are subjective feelings. However, as subjective measurements have some clear disadvantages, it would be interesting if we could measure comfort and discomfort objectively. However, information is lacking for the relationship between objective measurements and subjective comfort and discomfort experience in hand tool evaluation. Hence, the usefulness of objective measures for measuring comfort and discomfort are unknown. The main goal of the current study is to investigate the relationship between objective and subjective measures, by assessed comfort and discomfort.

Avoiding negative health effects and providing more job satisfaction for workers are not the only reason to pay attention to the design of comfortable hand tools. Employers also want their employees to achieve high work efficiency. Therefore, hand tools should stimulate high work efficiency too. Providing comfort and avoiding discomfort on the one hand and a high productivity on the other hand are not necessarily contradictive. Some studies suggest that hand tools which provide more comfort and less discomfort seem to be associated to a higher 
productivity (e.g., Eikhout, 2001). However, correlation coefficients are, as far as we know, not calculated yet. Hence, the second aim of the present study is to identify the relationship between comfort or discomfort and productivity when using hand tools.

To achieve both goals, a hand tool evaluation study was designed in which five hand saws were evaluated. The research questions are: 1) does a relationship exist between muscle activity (measured by EMG) and hand contact pressure (average pressure, pressure area and pressure-time (Pt-)integral) on the one hand and subjective ratings of comfort and discomfort on the other hand in using hand saws? 2) Is productivity related to subjective ratings of comfort and discomfort in using hand saws?

The results of this study can be helpful to interpret objective data in terms of comfort and discomfort and indicate the most relevant objective types of measurement for the evaluation of comfort and discomfort in using hand tools. Additionally, the results may subscribe the importance of focussing on comfort and discomfort in hand tool design, if relationships exist between productivity and more comfort and less discomfort.

\subsection{Methods}

\subsubsection{Design}

Five hand saws were evaluated by twelve subjects. The five hand saws have a different market sector and they differ in product characteristics, like hand grip, saw blade and teeth (Figure 7.1).
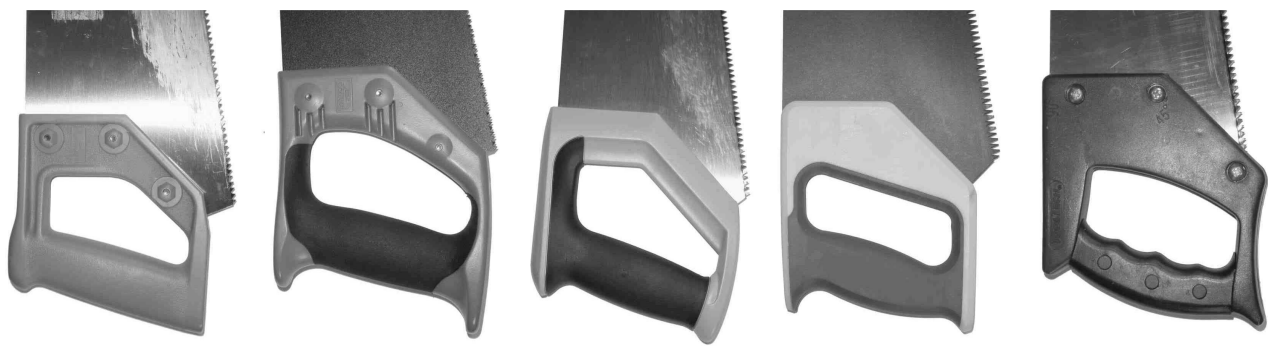

Figure 7.1 Five hand saws were evaluated in case study 3

The objective measurements were 1) EMG (\%MVC) of five muscles during two measurements, 2) static and dynamic contact pressure (average pressure, pressure area and pressure-time integral), and 3) productivity. Comfort and discomfort (local perceived discomfort) were subjectively measured. An overview of the dependent and independent variables is given in Table 7.1 (next page).

\subsubsection{Subjects}

Twelve male (professional) carpenters participated in this study. The subjects gave their written informed consent. Table 7.2 shows the demographics of the sample. 
Table 7.2 Demographics of the sample

\begin{tabular}{lcrl}
\hline & Range & Mean & SD \\
\hline Age (years) & $38-64$ & 50.2 & 8.6 \\
Stature (cm) & $169-190$ & 179.6 & 5.5 \\
Weight $(\mathrm{kg})$ & $70-98$ & 82.6 & 8.9 \\
Hand length $(\mathrm{cm})^{*}$ & $17.6-21.5$ & 20.1 & 1.2 \\
Hand width $(\mathrm{cm})$ & $7.7-10.2$ & 9.3 & 0.8 \\
Grip force $(\mathrm{N})$ & $121-227$ & 170 & 31 \\
\hline
\end{tabular}

* Measured from top of the middle finger to the distal crease of the wrist 
Table 7.1 Overview of the independent and dependent variables

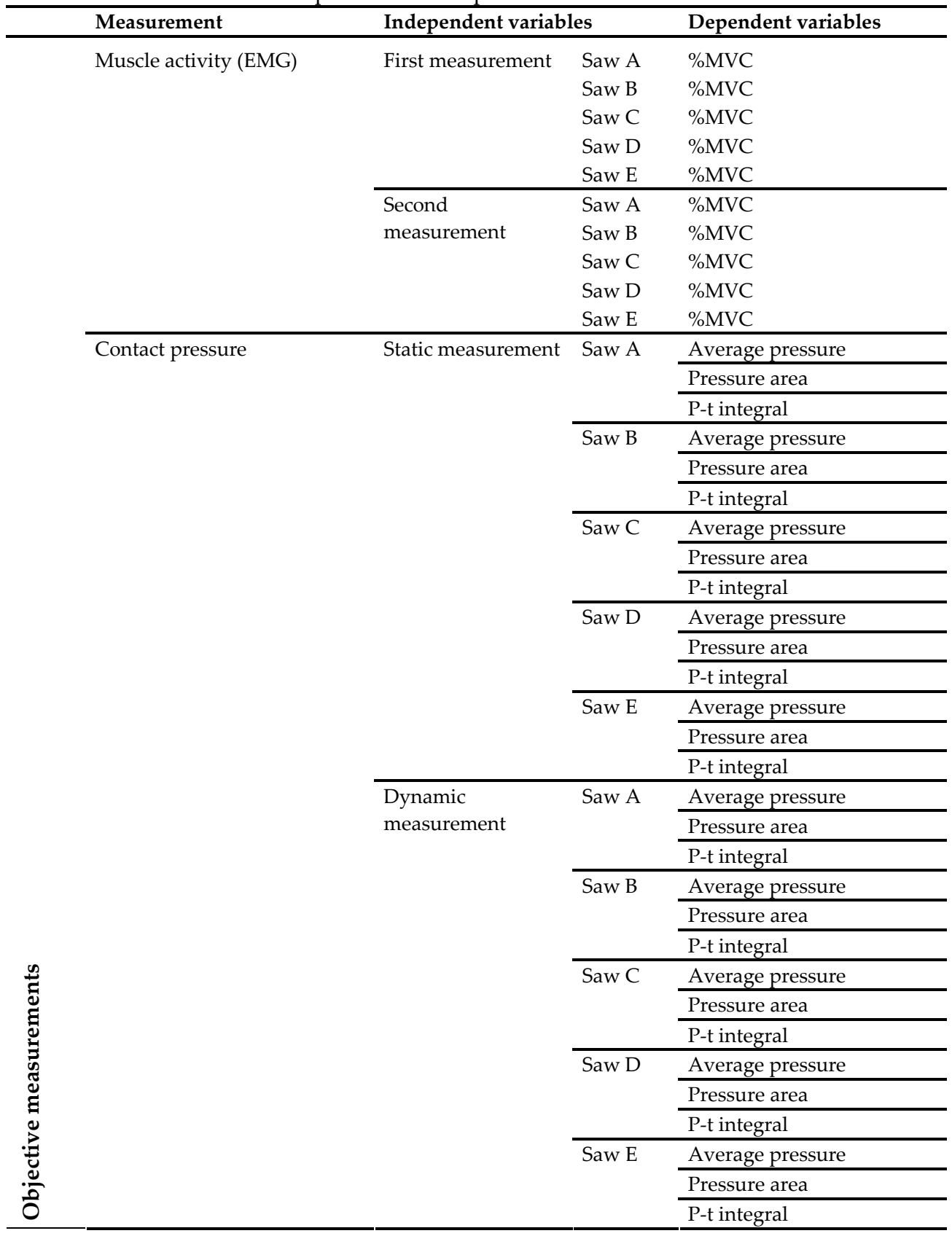


Table 7.1 (continued) Overview of the independent and dependent variables

\begin{tabular}{|c|c|c|c|}
\hline & Measurement & Independent variables & Dependent variables \\
\hline & \multirow[t]{5}{*}{ Productivity } & Saw A & Number of pieces cut \\
\hline & & Saw B & Number of pieces cut \\
\hline & & Saw $\mathrm{C}$ & Number of pieces cut \\
\hline & & Saw D & Number of pieces cut \\
\hline & & Saw E & Number of pieces cut \\
\hline \multirow{10}{*}{ 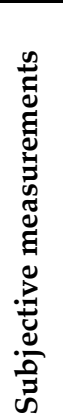 } & \multirow[t]{5}{*}{ Comfort } & Saw A & Rating $1-7$ \\
\hline & & Saw B & Rating $1-7$ \\
\hline & & Saw C & Rating 1-7 \\
\hline & & Saw D & Rating $1-7$ \\
\hline & & Saw E & Rating 1 - 7 \\
\hline & \multirow[t]{5}{*}{ Discomfort (LPD) } & Saw A & Sum of ratings of regions \\
\hline & & Saw B & Sum of ratings of regions \\
\hline & & Saw C & Sum of ratings of regions \\
\hline & & Saw D & Sum of ratings of regions \\
\hline & & Saw E & Sum of ratings of regions \\
\hline
\end{tabular}

\subsubsection{Tasks}

Static task

The static task was performed to measure contact pressure in statical circumstances. During the static contact pressure measurement, the subject put the tip of the hand saw blade against the adapter of a digital force gauge (MecMesin, AFG 100). The force gauge was attached to a wooden plate which was mounted in a direction of $35^{\circ}$ to the horizontal (Figure 7.2). The subjects were asked to generate an output force of $40 \mathrm{~N}$, while holding the hand grip of the hand saw as they were used to, except that now the hand mat was attached in the palm of the hand. During 10 seconds, the contact pressure was measured.

\section{Dynamic task}

The dynamic task (used to measure EMG, dynamic pressure, productivity, comfort and discomfort) was a standardized task of crosscutting a wooden beam (Figure 7.3). For this purpose, a beam of bankirai wood $(77 \times 82 \mathrm{~mm}$ ) was attached to a Workmate (height $59 \mathrm{~cm}$ ). 


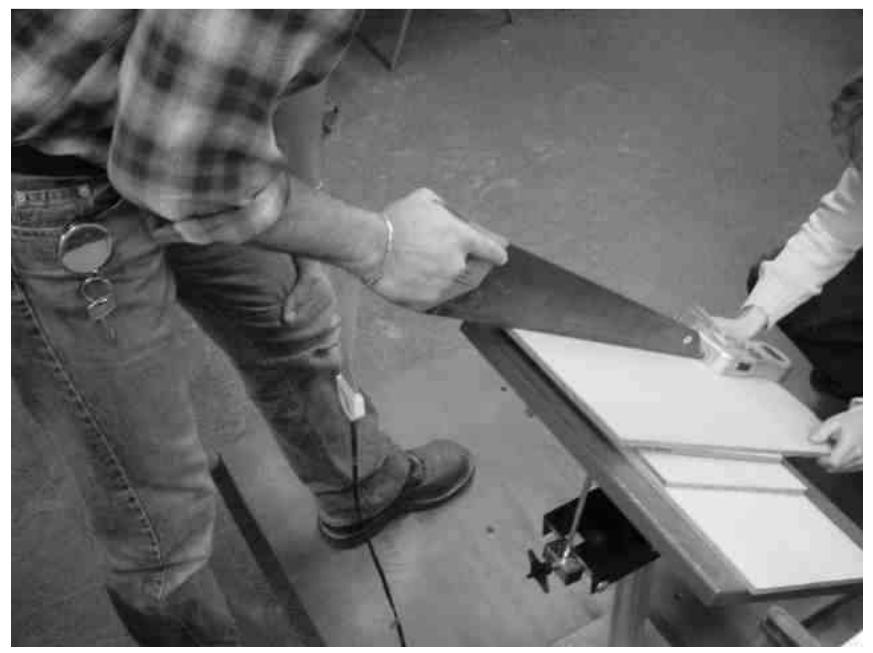

Figure 7.2 Static contact pressure measurement

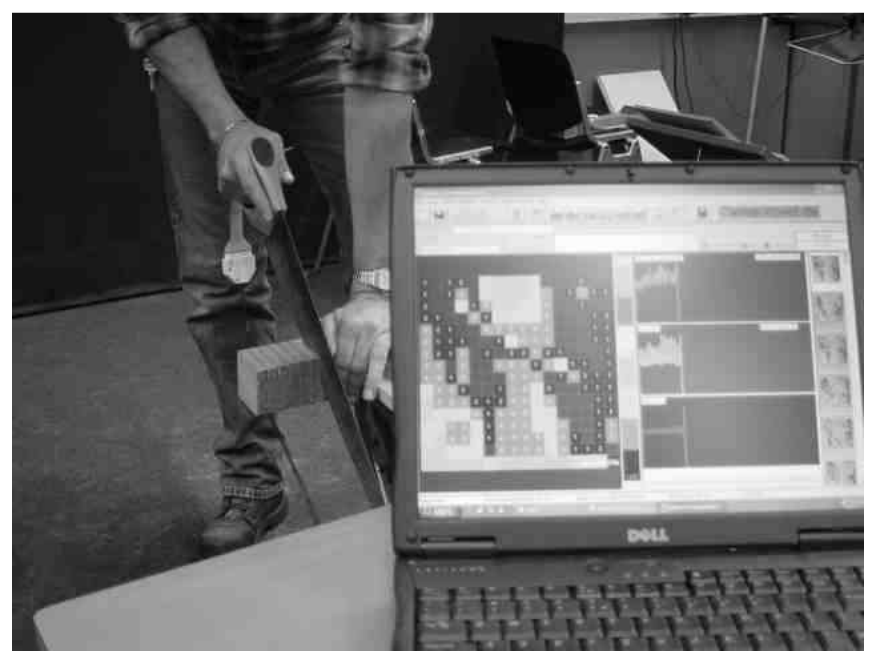

Figure 7.3 Dynamic contact pressure measurement

Bankirai wood was chosen because of its constant grains and absence of knots, which provide constant conditions for every saw for every subject. The place of the saw- cuts were drawn on the beam, with an intersection of $15 \mathrm{~mm}$. The subjects were told to maintain the same body posture during all conditions.

\subsubsection{Subjective measurements}

Both comfort and discomfort experience were measured using subjective measurement techniques.

\section{Comfort Questionnaire for hand tools}

The Comfort Questionnaire for Hand tools (CQH) is based on the results of a previous study in which descriptors associated with comfort in using hand tools were identified by end-users 
(Kuijt-Evers et al., 2005), e.g. hand tool fits the hand, has a good functionality, has a high task performance. For the current hand saw evaluation study 17 of these descriptors were selected. The subjects rated the items on a 7 -point scale ( $1=$ totally disagree, $7=$ totally agree). After the endusers rated to what extent the hand saw fulfils these descriptors, they rated overall comfort after short time use on a 7 -point scale (1=very uncomfortable, $7=$ very comfortable).

\section{Discomfort of arm and hand}

Discomfort was measured using the Local Perceived Discomfort (LPD) method (Groenesteijn et al., 2004). This method consisted of a detailed hand-wrist map, with 23 regions and a map of the upper extremity which consisted of four regions. Feelings of pain, numbness and pressure, tiredness underlie discomfort. A six point-scale was used to assess discomfort (ranging from $0=$ no discomfort,,.., to 5 = extreme discomfort, almost maximum) per region.

\subsubsection{Objective measurements}

$E M G$

Muscle activity was measured by means of surface electromyography (EMG, porti 16/ASD system, TMS, Enschede). Bipolar Ag/AgCl (Medicotest) surface electrodes were placed with an inter-electrode distance of $25 \mathrm{~mm}$ at five muscles at the subject's dominant side: $\mathrm{m}$. extensor carpi radialis, $\mathrm{m}$. flexor carpi radialis, $\mathrm{m}$. triceps brachii caput mediale, $\mathrm{m}$. trapezius pars descendens and $\mathrm{m}$. trapezius pars tranversa/m. romboideus major (electrode positions according to Franssen (1995)). A reference electrode was placed on C7 spinous process. EMG signals were sampled at $1000 \mathrm{~Hz}$ during 10 seconds.

\section{Contact pressure}

Contact pressure was recorded using the Novel Pliance-x system. The hand mat (Elastisens HA $44,70.4 \times 70.4 \mathrm{~mm} \mathrm{~cm}, 16 \times 16$ sensors) was attached to the palm of the hand using double-sided adhesive tape (Figure 7.4). The data were recorded using the Pliance software. Contact pressure was measured for all sensors with a sample frequency of $10 \mathrm{~Hz}$ during 10 seconds in static as well as dynamic circumstances. The accuracy of the Novel pressure measurement equipment is very high (Hochmann et al., 2002; Poliack et al., 1999). Within the pressure range (5-200 kPa), a linear relationship exists between the applied and the observed pressures under increasing applied load. The hysteresis (difference in pressure readings while increasing and then decreasing pressure at the same rate) is small (Polliack et al., 1999). Hochmann (2002) found a hysteresis smaller than $5 \%$. Drift errors (change in the relationship between applied and observed pressures over a period of time) are also small (Polliack et al., 1999). 


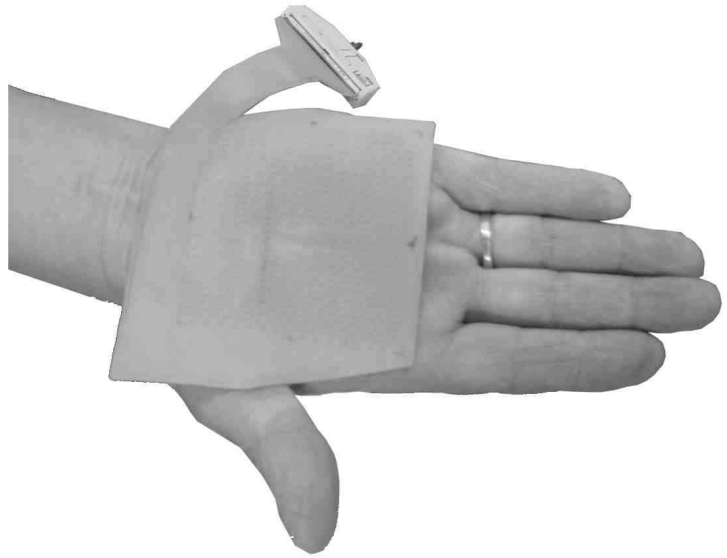

Figure 7.4 The hand mat was attached to the hand using double-sided adhesive tape 


\section{Productivity}

The productivity was expressed as the number of pieces of wood which were cut during three minutes. The unfinished last piece was registered as $1 / 4,1 / 2$ and $3 / 4$ piece of wood, depending on the area which was cut.

\subsubsection{Protocol}

The subject was informed about the study. After that, some general information was noted. Subsequently, the hand mat was attached to the hand. In order to illustrate the hand mat's position on the hand a photo was taken. Before contact pressure was measured, the hand mat was set to zero holding the hand in the position like the hand grip of the saw was held. Then, the contact pressure was measured during the static and the dynamic sawing tasks.

After the contact pressure measurements, the preferred movement frequency when crosscutting the beam was obtained. The results of a pilot study showed that the preferred motion rhythm did not differ very much between the five hand saws. Therefore we decided to determine the motion rhythm using one saw. Hand saw B was chosen because this saw caused the fastest motion rhythm. Carpenters stated that it is easier to adapt to a faster motion rhythm than to slow down. The amount of cycli and the time the task took were recorded. From this, the preferred movement frequency could be calculated in movements a minute. This motion rhythm was given by a metronome during the EMG measurements in the sawing task, to maintain the same movement frequency using different saws.

Then, the electrodes were applied over the muscle bellies, after the skin was shaved, scrubbed and cleaned with alcohol. Subsequently, static maximum voluntary contractions were obtained for each muscle using manual resistance. The isometric contractions lasted 2-3 seconds. This was repeated three times for each muscle. The largest of these contractions for each muscle was called the maximum voluntary contraction of that muscle (MVC). 
Before the sawing task started, the subject rated his LPD. Then, the subject had to saw five minutes. When sawing the first piece of wood, the EMG registration period started after the subject was accustomed to the motion rhythm of the metronome (EMG measurement 1). After the first piece of wood, the subject continued sawing during three minutes in his own rhythm (without metronome) to maintain the productivity. When the three minutes passed, the subject immediately stopped sawing the current piece and moved on to the next saw-cut. When sawing the first piece of wood after the three minute period, the subject again accustomed himself to the motion rhythm of the metronome and then again EMG was recorded (EMG measurement 2). After the saw-task was finished, the subjects rated their LPD and finished the CQH. Then, the subject had a rest period of at least five minutes. The saw-task was repeated for each hand saw, resulting in five sawing tasks for each subject. The order of hand saws was systematically varied among the subjects.

\subsubsection{Data analysis}

Discomfort (LPD)

Local perceived discomfort was rated before and after each sawing task. For each region the increase in discomfort was calculated by subtracting the perceived discomfort rating after the task from the perceived discomfort before the task. The sum of the local discomfort increase of all regions together constitutes the score of LPD. As the frequency distribution of the LPD shows a large degree of skewness, a logarithmic transformation was performed on this variable. In further analysis only the transformed LPD was used as a variable, which is called lnLPD.

\section{$E M G$}

An even number of saw cycli was cut from each 10 seconds lasting EMG measurement, with a minimum of 6 cycli. EMG signals were band pass filtered $(10-400 \mathrm{~Hz})$, rectified and filtered (fourth order Butterworth low pass $5 \mathrm{~Hz}$ ). Subsequently, the average EMG activity was calculated and normalized to the EMG level obtained during the MVCs.

\section{Contact pressure}

Static contact pressure

Pressure parameters were calculated in Matlab (The Mathworks). A cut-off pressure (20 kPa) was introduced to define pressure regions. A pressure region contains minimally 4 sensors having a pressure above the cut-off pressure. The average pressure, pressure area (area of all pressure regions together), and P-t integral were calculated.

\section{Dynamic contact pressure}


The dynamic pressure measurements were cut into 10 saw cycli. The same pressure variables were calculated as in the static contact pressure measurement.

\subsubsection{Statistics}

MANOVA repeated measures was performed to compare the hand saws with each other on EMG (\%MVC) and contact pressure (average pressure, pressure area and P-t integral) as both measurements deal with more than one independent variable. The independent variables during the EMG measurement were the hand saws (A to E) and the measurement moment (begin and end of sawing task). The independent variables of the contact pressure measurement were the hand saws (A to E) and the type of measurement (static and dynamic). ANOVA repeated measurements was performed to compare the hand saws on productivity as the hand saws (A to E) were the only independent variable during the productivity measurement. $p$ is based on degrees of freedom corrected with Greenhouse-Geisser's epsilon to compensate for the effects of violations of the sphericity assumption (Twisk, 2003). The results of the MANOVA and ANOVA will show if differences exist on EMG, contact pressure and productivity between the hand saws and between the measurements. However, based on these results it is not known between which groups (i.e., hand saws and measurements) the differences exist. Therefore a follow-up test is needed guarding against an increase in the probability of a type I error when performing multiple significance tests (Everitt, 2002). The Bonferroni follow-up was used for comparisons of the means between the groups. This is a highly conservative test, which means that it highly prevents for making the type I error and identifies fewer significant differences compared to other post-hoc tests (Thomas and Nelson, 1996).

Wilcoxon signed ranks test was used to see if the hand saws differ from each other on overall comfort and local perceived discomfort.

Linear regression analysis was performed to study the relationship between objective measurements (EMG, contact pressure, productivity) and subjective measurements (Overall comfort and $\operatorname{lnLPD}$ ). We chose to perform a linear regression analysis (and not a multiple linear regression analysis including all objective measurements at the same time) as we wanted to investigate the predictive value of each objective variable separately. As one subject tested all five hand saws, these data points were not independent. Therefore, we used general estimation equations (GEE) to analyse our data, because this statistical technique takes into account the within subjects correlation of our data (Twisk, 2003). However, data analysis with the sophisticated GEE technique with a categorical outcome variable is more problematic than with continuous or dichotomous outcome variables. Until recently, only simple methods (which do not correct for the dependence of our data points) were available to analyse categorical outcome variables. Therefore, categorical variables are treated as continuous variables in GEE analysis, especially when they are ordinal and have a sufficient number of categories (i.e., more than five) (Twisk, 
2003). In our study, the outcome variables (comfort and lnLPD) meet these requirements and therefore we considered our outcome variables as continuous variables in the GEE analysis. 


\subsection{Results}

\subsubsection{Comfort and discomfort}

Differences between hand saws

Overall comfort after short time use was different between hand saws. Hand saw A, B, C and D were assessed as significantly more comfortable than hand saw $E(p<.01)$. Hand saw E showed significantly more discomfort than the other hand saws $(\mathrm{p}<.05)$. The mean ranks of the comfort ratings and $\operatorname{lnLPD}$ are shown in Table 7.3.

Table 7.3 Mean ranks of the comfort ratings and the $\ln L P D$ for the five hand saws

\begin{tabular}{ccc}
\hline Saw & Comfort (mean rank) & lnLPD (mean rank) \\
\hline A & 3.36 & 3.25 \\
B & 4.00 & 2.50 \\
C & 3.23 & 2.83 \\
D & 3.32 & 2.42 \\
E & 1.09 & 4.00 \\
\hline
\end{tabular}

\subsubsection{EMG}

Differences between hand saws and moments of measurement

The differences in EMG between hand saws and moments of measurement were obtained for each muscle separately. The means of the \%MVC are shown in Table 7.4. The EMG of the m. trapezius pars transversa/m. romboideus major was different among the various hand saws. However, Bonferroni as post-hoc test did not show between which hand saws the difference existed. No significant differences were found between hand saws for the $\mathrm{m}$. extensor carpi radialis, the $\mathrm{m}$. flexor carpi radialis, the $\mathrm{m}$. triceps caput mediale, and the $\mathrm{m}$. trapezius pars descendens. When comparing the first to the second EMG measurement, the $\mathrm{m}$. trapezius pars descendens and the $\mathrm{m}$. trapezius pars transversa/m.romboideus major were the only muscles showing a significant difference, namely a higher \%MVC for the second measurement $(\mathrm{p}<.01)$. 
Table 7.4 Means and standard deviations of the \%MVC.

\begin{tabular}{|c|c|c|c|c|c|}
\hline \multirow[t]{3}{*}{ Muscle } & \multirow[t]{3}{*}{ Saw } & \multicolumn{2}{|c|}{ Measurement 1} & \multicolumn{2}{|c|}{ Measurement 2} \\
\hline & & \multicolumn{2}{|c|}{$\% \mathrm{MVC}$} & \multicolumn{2}{|c|}{$\%$ MVC } \\
\hline & & Mean & Std. & Mean & Std. \\
\hline \multirow[t]{5}{*}{ m. Triceps brachii } & A & 11.4 & 5.6 & 12.8 & 5.8 \\
\hline & $\mathrm{B}$ & 13.0 & 6.0 & 13.0 & 5.6 \\
\hline & $\mathrm{C}$ & 12.6 & 5.7 & 13.1 & 6.0 \\
\hline & $\mathrm{D}$ & 11.9 & 5.2 & 12.5 & 5.0 \\
\hline & E & 14.9 & 6.7 & 13.9 & 5.1 \\
\hline \multirow[t]{5}{*}{ m. Extensor carpi radialis } & A & 19.1 & 9.7 & 17.5 & 8.3 \\
\hline & $\mathrm{B}$ & 20.6 & 9.7 & 18.1 & 8.4 \\
\hline & $\mathrm{C}$ & 20.0 & 9.9 & 18.3 & 9.2 \\
\hline & $\mathrm{D}$ & 19.0 & 9.6 & 16.7 & 7.9 \\
\hline & $\mathrm{E}$ & 20.8 & 9.7 & 19.1 & 8.4 \\
\hline \multirow[t]{5}{*}{$\mathrm{m}$. Flexor carpi radialis } & A & 24.7 & 13.8 & 21.8 & 14.6 \\
\hline & B & 25.6 & 16.7 & 21.7 & 15.2 \\
\hline & $\mathrm{C}$ & 25.8 & 15.2 & 21.6 & 13.9 \\
\hline & $\mathrm{D}$ & 24.6 & 14.6 & 20.6 & 14.3 \\
\hline & $\mathrm{E}$ & 22.8 & 14.2 & 20.2 & 14.1 \\
\hline \multirow[t]{5}{*}{ m. Trapezius pars descendens } & $\mathrm{A}$ & 14.0 & 10.5 & 17.3 & 10.5 \\
\hline & $\mathrm{B}$ & 14.9 & 8.8 & 15.7 & 8.9 \\
\hline & $\mathrm{C}$ & 13.8 & 8.8 & 18.7 & 9.4 \\
\hline & $\mathrm{D}$ & 13.6 & 8.2 & 17.1 & 8.0 \\
\hline & $\mathrm{E}$ & 16.8 & 11.0 & 19.3 & 11.5 \\
\hline \multirow[t]{5}{*}{ m. Trapezius pars transversa } & $\mathrm{A}$ & 18.7 & 7.9 & 20.9 & 8.1 \\
\hline & B & 20.2 & 9.3 & 22.5 & 10.4 \\
\hline & $\mathrm{C}$ & 19.5 & 7.5 & 22.4 & 9.2 \\
\hline & $\mathrm{D}$ & 18.2 & 7.8 & 21.3 & 7.9 \\
\hline & $\mathrm{E}$ & 21.6 & 9.4 & 24.1 & 8.9 \\
\hline
\end{tabular}

Relationship with subjective measurements

Table 7.5 shows the standardized regression coefficients of the relationship between the mean \%MVC of the five muscles (m. extensor carpi radialis, $\mathrm{m}$. flexor carpi radialis, $\mathrm{m}$. triceps brachii caput mediale, $\mathrm{m}$. trapezius pars descendens and $\mathrm{m}$. trapezius pars tranversa/m. romboideus major) and comfort and discomfort.

Table 7.5 Standardized regression coefficients of the relationship between EMG (\%MVC) and overall

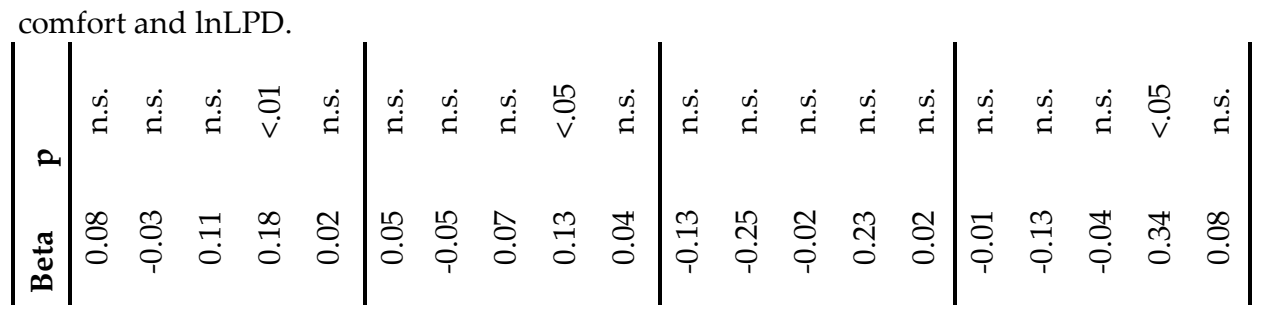




\begin{tabular}{|c|c|c|}
\hline Dependant variable & EMG measurement & Muscle \\
\hline \multirow[t]{10}{*}{ Overall comfort } & First measurement & m. extensor carpi radialis \\
\hline & & m. flexor carpi radialis \\
\hline & & m. triceps brachii caput mediale \\
\hline & & m. trapezius pars descendens \\
\hline & & m. trapezius pars transvers $/ \mathrm{m}$. romboideus major \\
\hline & Second measurement & m. extensor carpi radialis \\
\hline & & m. flexor carpi radialis \\
\hline & & m. triceps brachii caput mediale \\
\hline & & m. trapezius pars descendens \\
\hline & & m. trapezius pars transvers $/ \mathrm{m}$. romboideus major \\
\hline \multirow[t]{10}{*}{$\operatorname{lnLPD}$} & First measurement & m. extensor carpi radialis \\
\hline & & m. flexor carpi radialis \\
\hline & & m. triceps brachii caput mediale \\
\hline & & m. trapezius pars descendens \\
\hline & & m. trapezius pars transvers $/ \mathrm{m}$. romboideus major \\
\hline & Second measurement & m. extensor carpi radialis \\
\hline & & m. flexor carpi radialis \\
\hline & & m. triceps brachii caput mediale \\
\hline & & m. trapezius pars descendens \\
\hline & & m. trapezius pars transvers $/ \mathrm{m}$. romboideus major \\
\hline
\end{tabular}


Comfort was related to the mean \%MVC of the $\mathrm{m}$. trapezius pars descendens during the first (beta $=0.18$ ) and the second measurement (beta $=0.13$ ) with an explained variance of $1.6 \%$ and $3.2 \%$ respectively. A higher muscle activity of the trapezius pars descendens corresponded with more comfort.

Discomfort was also related to the mean \%MVC of the $\mathrm{m}$. trapezius pars descendens during the second measurement (beta $=0.34$; explained variance of $11.5 \%$ ). A higher muscle activity of this muscle corresponded with more discomfort.

\subsubsection{Contact pressure}

Differences between hand saws and measurements

Figures 7.5 to 7.7 show the average pressure, pressure area and the P-t integral of all hand saws for both the static and the dynamic measurement.

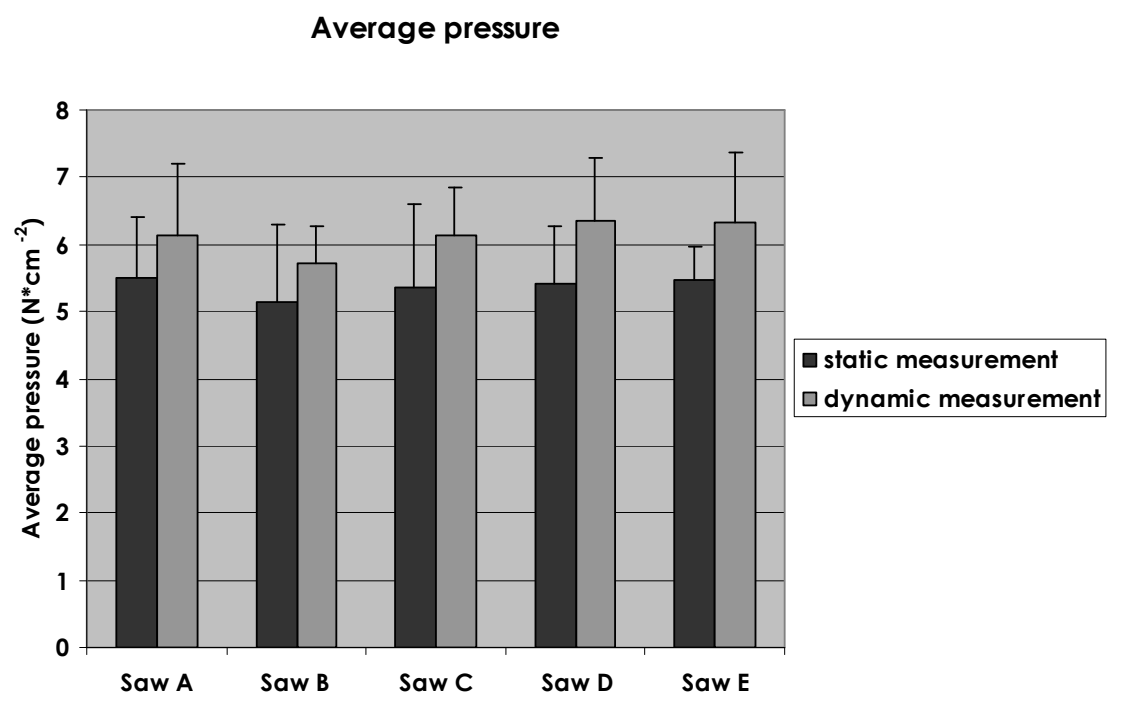

Figure 7.5 Average pressure on the palm of the hand during static and dynamic pressure measurements 


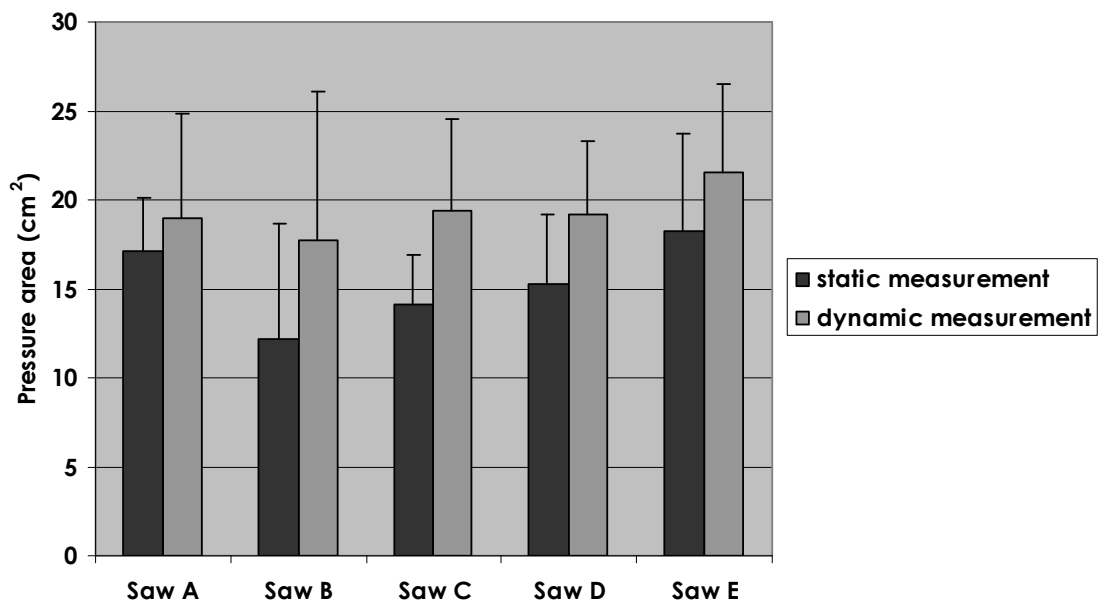

Figure 7.6 Pressure area on the palm of the hand during static and dynamic pressure measurements

\section{Pressure-time integral}

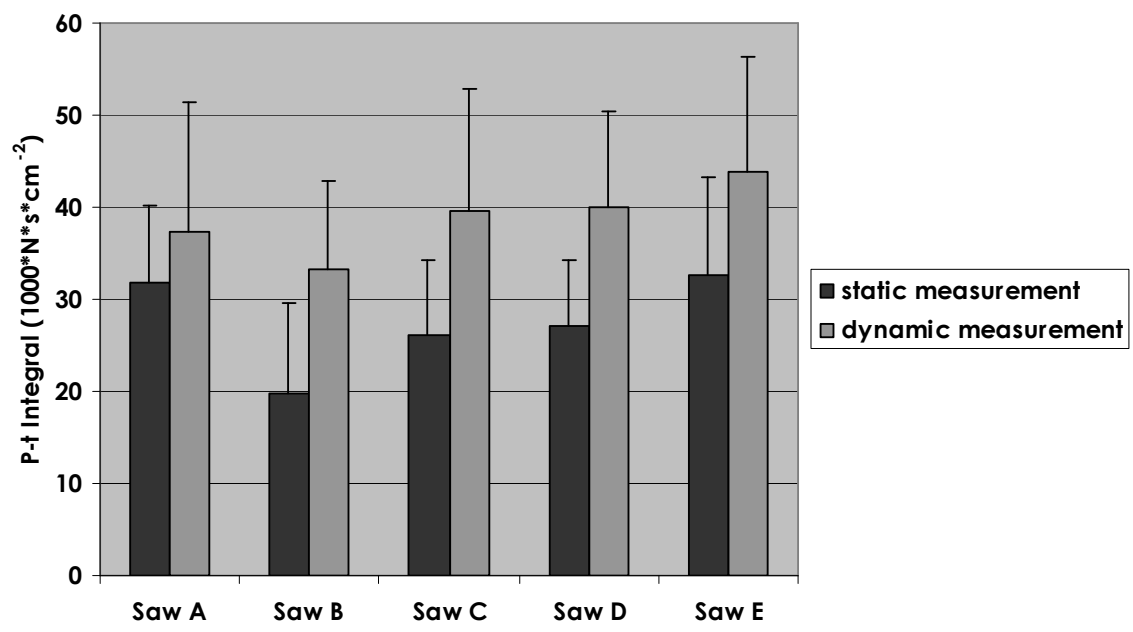

Figure 7.7 P-t integral of the pressure on the palm of the hand during static and dynamic pressure measurements

Significant differences between hand saws were found for average pressure $(\mathrm{p}<.05)$, pressure area $(\mathrm{p}<.01)$, and P-t integral $(\mathrm{p}<.01)$. For the average pressure, the Bonferroni post-hoc test did not show between which hand saws the differences existed. Additionally, the pressure area of hand saw E was significantly larger than the pressure area of hand saw B and D (both p<.05). Further, the P-t integral of hand saw B was significantly smaller than the P-t integral of A $(<.05), C(p<.05)$ and $E(p<.01)$. Figures $7.8 a$ and $b$ show the typical pressure area on the hand mat for hand saw $B$ and $\mathrm{E}$ of one person. 

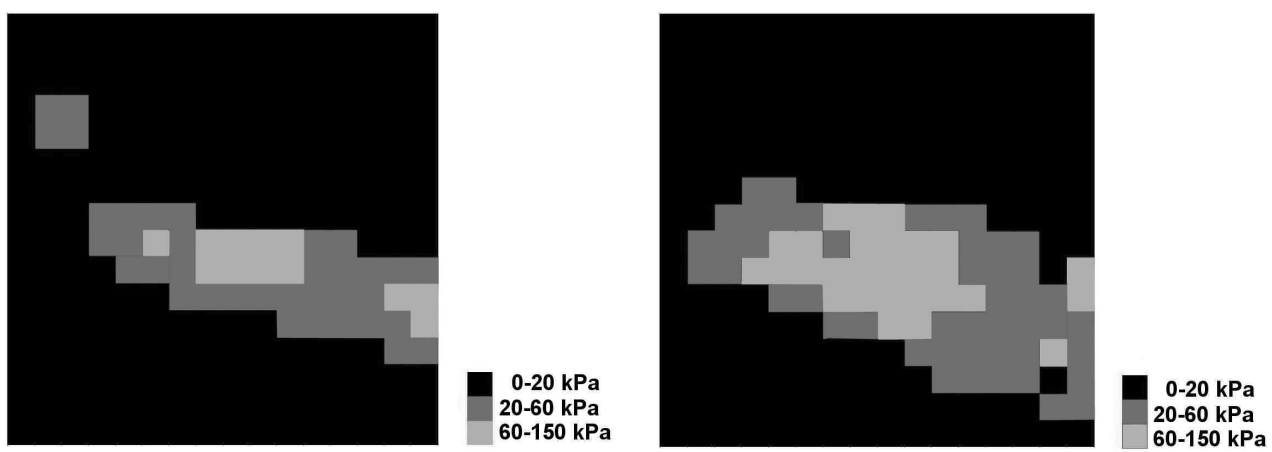

Figure 7.8a and 7.8b Pressure area of the hand saw in the hand for hand saw B and E respectively. The pressure area of hand saw E contains is larger (contains more sensors above the cutt-off pressure) than hand saw B.

Differences between static and dynamic measurement were found for all the contact pressure variables, i.e. average pressure $(\mathrm{p}<.05)$, pressure area $(\mathrm{p}<.01)$, and $\mathrm{P}-\mathrm{t}$ integral $(\mathrm{p}<.01)$. The average pressure, pressure area, and P-t integral were higher during the dynamic measurement compared to the static measurement. This implies that the exerted force $(40 \mathrm{~N})$ during the static measurement was an underestimation of the real output force which was exerted during sawing.

No interaction was found between hand saw and measurement for all the three pressure variables. The differences found between hand saws were independent of the type of measurement. 


\section{Relationship with subjective measurements}

Table 7.6 shows the standardized regression coefficients of the relationship between the contact pressure variables (average pressure, pressure area and P-t integral) and comfort and discomfort for both the static and dynamic measurements.

Comfort was best predicted by the P-t integral during the static measurement (beta=$0.24)$, which resulted in an explained variance of $5.8 \%$. The P-t integral was inversely related to the comfort experience, which means that a higher P-t integral corresponds to less comfort.

The best predictor of local perceived discomfort was the pressure area during the static pressure measurements (beta $=0.45$ ). The explained variance was $20.3 \%$. A larger pressure area corresponds to higher discomfort. The same phenomenon was observed for the P-t integral during static measurements, although the standardized regression coefficient for the P-t integral was somewhat lower (beta $=0.29$ ) with an explained variance of $8.4 \%$.

Table 7.6 Standardized regression coefficients of the relationship between contact pressure (average pressure, pressure area and P-t integral) and overall comfort and lnLPD for both static and dynamic measurements.

\begin{tabular}{lllcc}
\hline Dependant variable & Pressure measurement & & Beta & $\mathbf{p}$ \\
\hline Overall comfort & \multirow{2}{*}{ Static } & Average pressure & -0.14 & n.s. \\
& & Pressure area & -0.20 & n.s. \\
& & P-t integral & -0.24 & $<.01$ \\
\cline { 2 - 5 } & Dynamic & Average pressure & -0.04 & n.s. \\
& & Pressure area & -0.17 & n.s. \\
& Static & P-t integral & -0.18 & n.s. \\
\hline \multirow{2}{*}{$\operatorname{lnLPD}$} & & Average pressure & -0.05 & n.s \\
& & Pressure area & 0.45 & $<.01$ \\
\cline { 2 - 5 } & Dynamic & P-t integral & 0.29 & $<.01$ \\
\hline & & Average pressure & -0.05 & n.s. \\
& & Pressure area & 0.17 & n.s. \\
& & P-t integral & -0.12 & n.s. \\
\hline
\end{tabular}




\section{Influence of size of the hand}

The length and the width of the hand are confounding factors in the relationship between pressure area and discomfort. The length and the width of the hand affected the pressure area, but they were not related to discomfort.

\subsubsection{Productivity}

\section{Differences between hand saws}

Figure 7.9 shows the productivity of the carpenters with the different hand saws. Significant differences were found between saws $(\mathrm{p}<.01)$. When the carpenters used hand saw $\mathrm{E}$, they cut significant fewer pieces of wood than with the other hand saws $(\mathrm{p}<.05)$. Additionally, they also cut significantly fewer pieces of wood with hand saw B than with hand saw C and D.

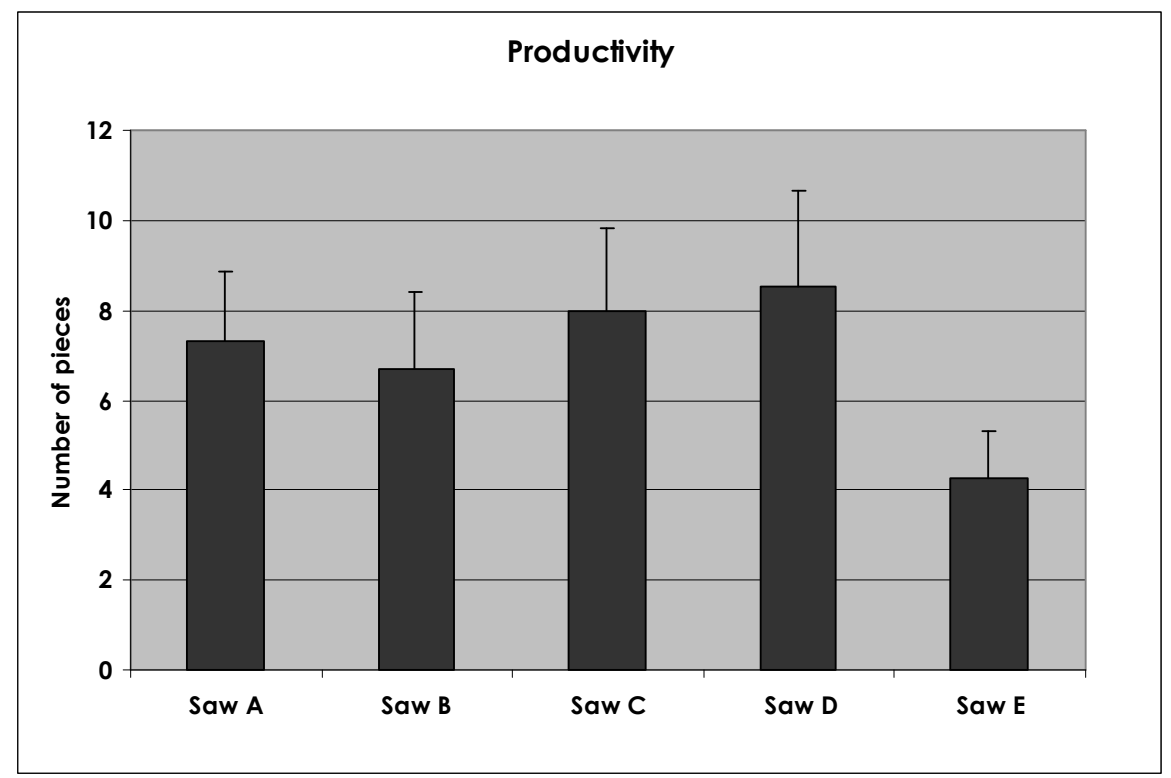

Figure 7.9 Productivity, number of wooden pieces cut in three minutes 


\section{Relationship with subjective measurements}

Productivity was related to overall comfort (beta $=0.31, \mathrm{p}<.01$ ) with an explained variance of $9.6 \%$ and inversely related to $\operatorname{lnLPD}$ (beta=-0.49, $\mathrm{p}<.01$ ) with an explained variance of $24.0 \%$. Hence, a higher productivity was achieved with hand saws which had a higher comfort rating. On the other hand, using hand saws which cause discomfort resulted in a lower productivity.

\subsection{Discussion}

In this study the relationships between objective measurements (i.e. contact pressure, EMG and productivity) and subjective comfort and discomfort experience were studied. Before the relationships were studied, the differences between the hand saws were considered. Although, the hand saws differed in design (the hand grip as well as the saw blade), they all look similar regarding quality, shape and size, except for hand saw E. In order to calculate the relationships it would have been better if more differences between hand saws existed. On the other hand, when these results are applied to hand tool evaluation studies nowadays, the differences between hand tools of the same kind will be very small and still it would be good if differences could be shown. In next sections, the relationships between objective measurements and experienced comfort/discomfort will be discussed.

\subsubsection{Relationship between EMG and comfort/discomfort.}

The results of the EMG measurements were contradictory. On the one hand, a small but positive relationship existed between the \%MVC of the $\mathrm{m}$. trapezius pars descendens and comfort $(\mathrm{p}<.01$ and $\mathrm{p}<.05$ for respectively the first and the second measurement) and on the other hand, a positive relationship existed with discomfort $(\mathrm{p}<.05)$. The latter was expected: a higher \%MVC of the $\mathrm{m}$. trapezius pars descendens should correspond to more discomfort. This hypothesis was based on a study of Hammarskjöld and Harms-Ringdahl (1992). They showed that the EMG median amplitudes increased after fatigue. We translated these results into our hypothesis: an increase in fatigue would also result in an increase of discomfort. The relationship between the $\% \mathrm{MVC}$ and discomfort was found to be stronger (11.5\% explained variance) than the relationship between the \%MVC and comfort (1.6\% and 3.2\% explained variance).

Two reasons can be given to explain that we did not find strong relationships between muscle activity and comfort or discomfort. The first reason is that the differences in \%MVC were small (maximum about 3\%) between the hand saws. Although, ANOVA repeated measures indicated that there were significant differences, Bonferroni as post-hoc test did not show between which hand saws the differences existed. Probably, people can not experience a difference in discomfort based on these small differences in \%MVC. The second reason is that there are many factors which can influence muscle activity (i.e., adjusted movement trajectories, 
alternating activation of different muscles) in a dynamic task. We expect that in more static and/or precision tasks (like using dentist tools), EMG may be more associated with measuring comfort/discomfort as other studies have shown an increase of EMG activity with increased precision demands (Milerad and Ericson, 1994; Visser et al., 2004).

\subsubsection{Relationship between contact pressure and comfort/discomfort}

\section{Static pressure measurement}

Contact pressure variables were related to comfort and discomfort. The P-t integral during static pressure measurement was inversely related to comfort $(\mathrm{p}<.01)$. Pressure area and the P-t integral during static pressure measurement were both positively related to discomfort $(\mathrm{p}<.01)$. This is subscribed by a study of Chen et al. (1994). They studied the relationship between pressure under the foot and insole comfort. Subjects were asked to rank four insoles from least comfortable to most comfortable. They found that the P-t integral and the contact area of the foot were significantly smaller for the most comfortable insole compared to the least comfortable insole.

The findings of the current study and the study of Chen et al. (1994) seem to be contradictory with the common opinion that a force distribution over a large area leads to less discomfort. However, in our study the average pressure remains more or less constant between the hand saws. Hence, the same average pressure was exerted on a larger area when using the hand saw which caused most discomfort (i.e. hand saw E). Goonetilleke and Eng (1994) explained this phenomenon by spatial summation (which means that simultaneous stimulation of many sensory receptors is required to arouse a stimulation). Alternatively, a greater sensory response is experienced with a larger stimulated area. Based on this fact, Goontilleke and Eng (1994) argue that when sensations tend towards discomfort, a pressure distributed over a large area may increase discomfort opposed to the same pressure over a small area. Hence, the decision to distribute or concentrate forces is dependent on the magnitude of the pressure exceeding a critical pressure for given surface area, like the palm of the hand. Consequently, the relationship found between contact area and discomfort can not be applied to other hand tools right away as the pressure for the given surface area may be under the critical pressure for the palm of the hand.

For application to other hand tool evaluation studies or hand tool (re)design, first of all, the critical pressure for the specific contact area in the hand should be studied. Then the designer ought to know whether or not the pressure on the hand -when using the hand tool- will exceed this critical value. Subsequently, the designer knows whether he should enlarge or reduce the contact area of the design of the hand grip in order to avoid discomfort.

\section{Dynamic pressure measurement}


We did not find a relationship between dynamic pressure measurements and discomfort, while we did for static pressure measurements. From the results of MANOVA, it was seen that no interaction effect existed for saw and measurement. This means that the differences which were found between the saws were the same for the dynamic and the static measurements. This is remarkable because the five hand saws did not only have different hand grips, but they also differed in saw blade (i.e., surface material, teeth count, teeth size). During the static pressure measurements only the influence of the hand grip was measured, while in the dynamic pressure measurements a combination of hand grip and saw blade played a role. It was expected that the saw blade would affect the push force and affect the contact pressure during the dynamic measurements. However, the saw blade did not seem to have any influence.

From this, it can be concluded that the shape of the hand grip plays a major role in contact pressure in hand saws. As the contact area affects the discomfort experience, the static contact pressure measurement can be used to optimize the shape of the hand grip in order to avoid discomfort. The design of the saw blade (or the work side of the tool) can not be evaluated by contact pressure measurement, especially not when the hand grips differ. In that case, the hand grips will overrule the effects of the saw blade, such as this study illustrated.

In conclusion, static pressure measurement (i.e. contact area) could predict comfort/discomfort better than dynamic pressure measurement in sawing.

\subsubsection{Relationship between productivity and comfort/discomfort}

The results of this study showed that productivity is closely related to comfort and discomfort. The productivity was higher for hand saws that were assessed as more comfortable and the productivity was lower for hand saws which caused discomfort. The relationship between productivity and discomfort was earlier found in an evaluation study of scrapers (Eikhout et al., 2001). The scraper which needed fewer scrape motions was considered to be very comfortable by the painters and caused significantly less discomfort in the upper extremity. For hack saws, Das et al. (2005) also found a higher productivity with the hack saw which was subjectively assessed as better.

Groenesteijn et al. (2004) did not find any differences in productivity between the plier which was addressed as best-feeling by $80 \%$ of the subjects and the other pliers. They did not find any significant differences in local perceived discomfort either. Maybe the design of the pliers differed not enough to measure differences in productivity. However, the experienced work velocity was higher for the plier which was rated more comfortable than the others. This is an interesting finding with respect to the question if a more comfortable hand tool results in a higher productivity, or inversely, if a hand tool with which one can reach a higher productivity is experienced as more comfortable. It seems that the experience of productivity plays an important role in assessing comfort. This indicates that an (experience of) high productivity may affect the 
comfort experience in a positive way. This is subscribed by an earlier study in which a positive relationship (beta $=0.69, \mathrm{p}<.01$ ) was found between the experience of high task performance and the overall comfort experience by using screwdrivers (Kuijt-Evers et al., 2005). Additionally, it seems obvious that when a hand tool causes discomfort (like sore muscles and pressure on the hand), one can not continue the task at high velocity or even without a break. Hence, feelings of discomfort can cause a decrease of productivity and (experiences of) high productivity may increase the comfort experience.

As a result, the focus on avoiding discomfort in hand tool design is not only important to avoid musculoskeletal complaints and improve job satisfaction of users, but is also important from a productivity point of view.

\subsection{Conclusion}

Based on our findings we conclude that EMG measurements can not be used as an objective measurement to subscribe subjective measured comfort or discomfort experience using hand tools for dynamic tasks. Contact pressure can not be used as a predictive measurement of comfort experience too. On the other hand, contact pressure (i.e., pressure area) is an appropriate objective measurement to support subjective findings on discomfort in using hand tools. Moreover, this contact pressure measurement can be useful to designers in hand grip design. Additionally, from the productivity point of view, it is also important to design comfortable hand tools as they affect productivity in a positive way.

\subsection{Acknowledgements}

We would like to thank the Dutch Ministry of Economic Affairs, Stichting Arbouw and Bahco Tools for their support.

\subsection{References}

Annet, J. 2002. Subjective rating scales: science of art? Ergonomics, 45 (14): 966-987.

Chang, S.R., Park, S., Freivalds, A., 1999. Ergonomic evaluation of the effects of handle types on garden tools. International Journal of Industrial Ergonomics, 24 (1): 99-105.

Chen, H., Nigg, B.M., Koning, J. de, Relationship between plantar pressure distribution under the foot and insole comfort. 1994. Clinical Biomechanics, 9 (6): 335-342.

Côté, J.N., Mathieu, P.A., Levin, M.F., Feldman, A.G., 2002. Movement reorganization to compensate for fatique during sawing. Exp. Brain.Res., 146: 394-398 
Das, B., Jongkol, P., Ngui, S., 2005. Snap-on-handles for a non-powered hacksaw : An ergonomics evaluation, redesign and testing. Ergonomics, 48 (1): 78-97.

Eikhout, S.M., Bronkhorst, R.E. and Grinten, M.P. van der., 2001. Evaluation of a new scraper. Proceedings of the 45th HFES congress 2001, Minneapolis (US): HFES: CD rom: 722-726

Everitt, B.S., 2002. The Cambridge dictionary of statistics. 2nd edition. Cambridge University Press, Cambridge: 50.

Fellows, G.L., Freivalds, A., 1991. Ergonomic evaluation of a foam rubber grip for tool handles. Applied Ergonomics. 22 (4): 225-230.

Franssen, J.L.M., 1995. Handboek Oppervlakte Elektromyografie. De Tijdstroom, Utrecht.

Freund, J., Takala, E-P., Toivonen, R., 2000. Effects of two ergonomics aids on the usability of an in-line screwdriver. Applied Ergonomics, 31 (4): 371-376.

Goonetilleke, R.S., Eng, T.J., 1994. Contact area effects on discomfort. Proceedings of the Human Factors and Ergonomics Society 38th Annual Meeting. 688-690.

Groenesteijn, L., Eikhout, S.M., Vink, P., 2004. One set of pliers for more tasks in installation work: the effects on (dis)comfort and productivity. Applied Ergonomics, 35 (5): 485-492.

Habes, D.J., Grant, K.A., 1997. An electromyographic study of maximum torques and upper extremity muscle activity in simulated screwdriving tasks. International Journal of Industrial Ergonomics, 20 (4): 339-346.

Hammarskjöld, E., Harms-Ringdahl, K., 1992. Effect of arm-shoulder fatigue on carpenters at work. European Journal of Applied Physiology, 64 (5): 402-409.

Hochmann, D., Diesing, P., Boenick, U. 2002. Evaluierung der messmethoden zur bewertung des therapeutischen nutzens von antidekubitys-systemen. Biomedizinische Technik. 47: Ergängzungsband, S. 816-35.

Kadefors, R., Areskoug, A., Dahlman, S., Kilbom, Å., Sperling, L., Wikström, L., Öster, J. 1993. An approach to ergonomics evaluation of hand tools. Applied Ergonomics. 24 (3): 203-211.

Kilbom, Å., Mäkäräinen, M., Sperling, L., Kadefors, R., Liedberg, L. 1993. Tool design, user characteristics and performance: a case study on plate shears. Applied Ergonomics. 24 (3): 221-230.

Kluth, K., Kelermann, H.G., Strasser, H., 2004. Assessment of the ergonomic quality of file handles using electromyographic and subjective methods. Occupational Ergonomics, 4 (2): 133-142.

Kong, Y-K, Freivalds, A., 2003. Evaluation of meat-hook handle shapes. International Journal of Industrial Ergonomics, 32 (1): 13-23.

Kuijt-Evers, L.F.M., Twisk, J.W.R., Groenesteijn, L., Looze, M.P. de, Vink, P. 2005. Identifying predictors of comfort and discomfort in using hand tools. Ergonomics, 48 (6): 692-702.

Lee, K.S., Ferraiuolo, P., Temming, J., 1993. Measuring seat comfort.Automotive Engineering. 101(7): 25-30.

Li, K.W., 2003. Ergonomic evaluation of a fixture used for power driven wire-tying hand tools. International Journal of Industrial Ergonomics. 32: 71-79.

McGorry, R.W., Dowd, P.C., Dempsey, P.G., 2003. Cutting moments and grip forces in meat cutting operations and the effect of knife sharpness. Applied Ergonomics, 34 (4): 375-382.

Milerad, E., Ericson, M.O., 1994. Effects of precision and force demands, grip diameter, and arm support during manual work: an electromyographic study. Ergonomics. 37: 255-264.

Niëmelä, T., Leppanen, M., Päivinen, 2000. Evaluation of an experimental testing system for non-powered hand tools. In: Ergonomics for the New Millennium. Proceedings of the IEA/HFES 2000 congres. 30 July-4 August, San Diego CA: 3-643-646.

Polliack, A., Landsberger, S., McNeal, D., Sieh, R., Craig, D., Ayyappa, E. 1999. Socket measurement systems perform under pressure. Biomechanics. June: 71-80.

Strasser, H., Wang, B., Hoffmann, A., 1996. Electromyography and subjective evaluation of hand tools: The example of masons' trowels. International Journal of Industrial Ergonomics, 18 (1): 91-106.

Thomas, J.R., Nelson, J.K., Research methods in physical activity. (Leeds, Human Kinetics): 158. 
Twisk, J.W.R., 2003. Applied longitudinal data analysis for epidemiology. Cambridge University Press, Cambridge.

Visser, B., Looze, M.P de, Graaff, M.P. de, Dieën, J.Hv. van, 2004. Effects of precision demands and mental pressure on muscle activation and hand forces in computer mouse tasks. Ergonomics, 47 (2): 202-217. 